\title{
The Port Pirie cohort study: maternal blood lead and pregnancy outcome
}

\author{
ANTHONY J MCMICHAEL, ${ }^{1}$ GRAHAM V VIMPANI, ${ }^{2}$ EVELYN F ROBERTSON, ${ }^{3}$ \\ PETER A BAGHURST, ${ }^{1}$ AND PETER D CLARK ${ }^{4}$ \\ From the Division of Human Nutrition, ${ }^{1}$ Commonwealth Scientific and Industrial Research Organization \\ (Australia), Kintore Avenue, Adelaide, South Australia, 5000; the Child, Adolescent and Family Health \\ Service, ${ }^{2}$ South Australian Health Commission; the Department of Chemical Pathology, ${ }^{3}$ Adelaide Children's \\ Hospital; and formerly, Public Health Section, ${ }^{4}$ South Australian Health Commission
}

SUMmary During a three-year period, 831 pregnant women in and around Port Pirie, South Australia - a lead smelter community with longstanding lead pollution- were enrolled in a cohort study to examine prospectively the relation between body lead burden and pregnancy outcome. Three-quarters of the enrolled women were residents of the Port Pirie municipality; the other women lived in adjacent towns and countryside. At 14-20 weeks' gestation, the Port Pirie resident women had a mean blood lead concentration of $10.6 \mu \mathrm{g} / \mathrm{dl}$, while the mean in the other (non-Port Pirie) women was $7.6 \mu \mathrm{g} / \mathrm{dl}$. Similar differences were observed in maternal blood samples taken ato 30-36 weeks, at delivery, and from the umbilical cord. These blood lead measures, in conjunctions with information collected on other risk factors, were then examined in relation to pregnancy outcome. Among 749 pregnancies followed to completion, pre-term delivery was statistically significantly associated, in a dose-response manner, with maternal blood lead concentration ato delivery. Mothers of late fetal deaths (stillbirths) had blood lead concentrations at 14-20 weeks'0 gestation similar to those of all the other women but had lower concentrations at delivery than theo other women. Outcomes of pregnancy for which no association with blood lead was detected were. spontaneous abortion, low birthweight (for births at term), intrauterine growth retardation, premature rupture of the membranes, and congenital anomalies.

Adverse effects of high lead concentrations in maternal blood on pregnancy outcome have been well documented over the past century. ${ }^{1}$ Such concentrations, occurring particularly within certain occupational environments, were reported in the 19 th century to have a deleterious effect on fertility, the course of pregnancy, and the development of the fetus. However, there is little information available on the obstetric consequences of lesser elevations of maternal blood lead such as occur within contemporary industrialised urban populations.

In Missouri, USA, community environmental lead exposure was associated with an increased incidence of premature rupture of the membranes and pre-term delivery. ${ }^{2}$ A subsequent study in a lesser exposed community in Louisville, Kentucky, found no such relation. ${ }^{3}$ Animal studies have shown that lead interferes with collagen synthesis, ${ }^{4}$ energy metabolism, and membrane structure,$^{5}$ all of which may adversely affect the chorioamniotic membrane and predispose to premature rupture of membranes.
Lead concentrations in umbilical cord blood have been reported to be positively correlated with an increased risk for minor congenital anomalies. ${ }^{6}$

In 1979, a long-term cohort study was begun of body lead burden in relation to pregnancy outcome and early childhood development in the population living in and around the city of Port Pirie. Port Pirie, a coastal city of 15000 people located 200 kilometres north of Adelaide (the capital of South Australia), is predominantly a lead smelter community, having one of the world's largest and oldest lead smelters located upwind on its immediate periphery.

This paper reports the relation, in that cohort of women, of pregnancy outcome to maternal blood concentrations measured during pregnancy and at delivery.

\section{Materials and methods}

During three years, May 1979 to May 1982, 831 pregnant women were enrolled for prospective study. 
These women, from Port Pirie $(n=646)$ and the surrounding rural area and neighbouring towns $(n=185)$, accounted for an estimated $90 \%$ of all newly occurring pregnancies within the specified source population. Inclusion of women from outside Port Pirie provided a second source of comparison beyond that afforcied by the inter-individual variation in blood lead concentration among women resident in Port Pirie.

Following a publicity campaign that immediately preceded the study, all women newly attending for antenatal care were advised by their doctor of the nature and purpose of the study and were encouraged to contact the study coordinator (an experienced community health nurse) to discuss and arrange participation.

A standardised questionnaire-interview was subsequently administered by the coordinator, seeking demographic, residential, occupational, educational, and dietary information together with medical and reproductive history and information on smoking and drinking habits. Information on husband's occupation was used to assign a binary social class status, "blue-collar" versus "white-collar". In the majority of women this interview and collection of a first blood sample occurred at the 14-20 week stage of gestation, although 257 (ie, 31\%) participants were enrolled sufficiently early for the interview and an additional blood sample to be taken prior to 14 weeks' gestation. This additional blood sample was subsequently useful in analyses relating to spontaneous abortion, the majority of which occurred before 14 weeks' gestation.

In addition to the blood sample routinely collected at 14-20 weeks' gestation, samples were also collected at around 32 weeks' gestation and at delivery. A sample was collected from the umbilical cord. In subsequent data analysis, depending on which outcome of pregnancy was being studied, the most appropriate single blood sample and/or a composite index based on serial samples was used. Further questionnaire-interviews were conducted at the time of each blood collection.

The blood samples were collected by venepuncture. Blood was collected from a forearm vein after the skin had been cleansed with an alcohol scrub (Webcol 4403) for at least 20 seconds and allowed to dry; $10 \mathrm{ml}$ of blood was drawn into a lead-free syringe and placed in a lead-free heparinised container, capped and mixed for 30 seconds. Samples were stored at $4^{\circ} \mathrm{C}$ and were transported to the Adelaide Children's Hospital laboratory within 24 hours of collection. Packed cell volume was measured on arrival at the laboratory.
Lead concentration was estimated by complexing the lead with ammonium pyrrolidine dithiocarbamate, extracting into 4-methylpentan-2-one, and measuring the lead in the organic phase by electrothermal atomisation atomic absorption spectrometry. ${ }^{7}$ The laboratory takes part in three major external quality control programmes for measurement of blood lead: the Wolfson Research Laboratories "National Quality Control Scheme", the Commonwealth of Pennsylvania's Department of Health "Lead Proficiency Testing Survey", and the programme conducted by the $\mathrm{CH} 6$ Committee of the Standards Association of Australia. Assays were done by one of two laboratory technologists expert in the technique. All blood lead concentrations were standardised to a packed cell volume of $35 \%$ for maternal blood and $50 \%$ for cord blood.

Details of the outcome of pregnancy were obtained within two days of delivery by interviewing the mother and by review of clinical records. The study coordinator was trained in assessing neonatal maturity by the Dubowitz procedure ${ }^{8}$ and examined 472 of the babies within 72 hours of delivery. In assessing intrauterine growth retardation, the appropriateness of birthweight for gestational age was determined from published tables. ${ }^{9}$

Relations between pregnancy outcome measures and potential explanatory variables were investigated by multiple (logistic) regression techniques appropriate to the nature of each outcome variable. Further details of model construction are discussed in the Results section.

\section{Results}

The age distributions of the 831 women presenting for the 14-20 weeks' interview are shown (table 1) for the Port Pirie (PP) and the non-Port Pirie (NP) women separately. The distributions are similar. Among the PP women, $85 \%$ had lived in Port Pirie for at least three years, while $79 \%$ and $70 \%$ had lived there for at least five and 10 years, respectively.

A branching diagram of the outcome of pregnancy in the study population is shown in the figure.

Table 1 Age and place of residence of the study population (figures in parentheses are row percentages)

\begin{tabular}{lllllll}
\hline \multirow{6}{*}{$\begin{array}{l}\text { Place of } \\
\text { residence }\end{array}$} & $<20$ & $20-24$ & $25-29$ & $30-34$ & $\geqslant 35$ & Total \\
\cline { 2 - 7 } & & & & & & \\
\hline Port Pirie & $50(7 \cdot 7)$ & $240(37 \cdot 2)$ & $236(36 \cdot 5)$ & $89(13 \cdot 8)$ & $31(4 \cdot 8)$ & $646(100 \cdot 0)$ \\
Non-Port Pirie & $10(5 \cdot 4)$ & $63(34 \cdot 0)$ & $81(43 \cdot 8)$ & $22(11 \cdot 9)$ & $9(4 \cdot 9)$ & $185(100 \cdot 0)$ \\
Totals & $60(7 \cdot 2)$ & $303(36 \cdot 5)$ & $317(38 \cdot 1)$ & $111(13 \cdot 4)$ & $40(4 \cdot 8)$ & $831(100 \cdot 0)$ \\
\hline
\end{tabular}




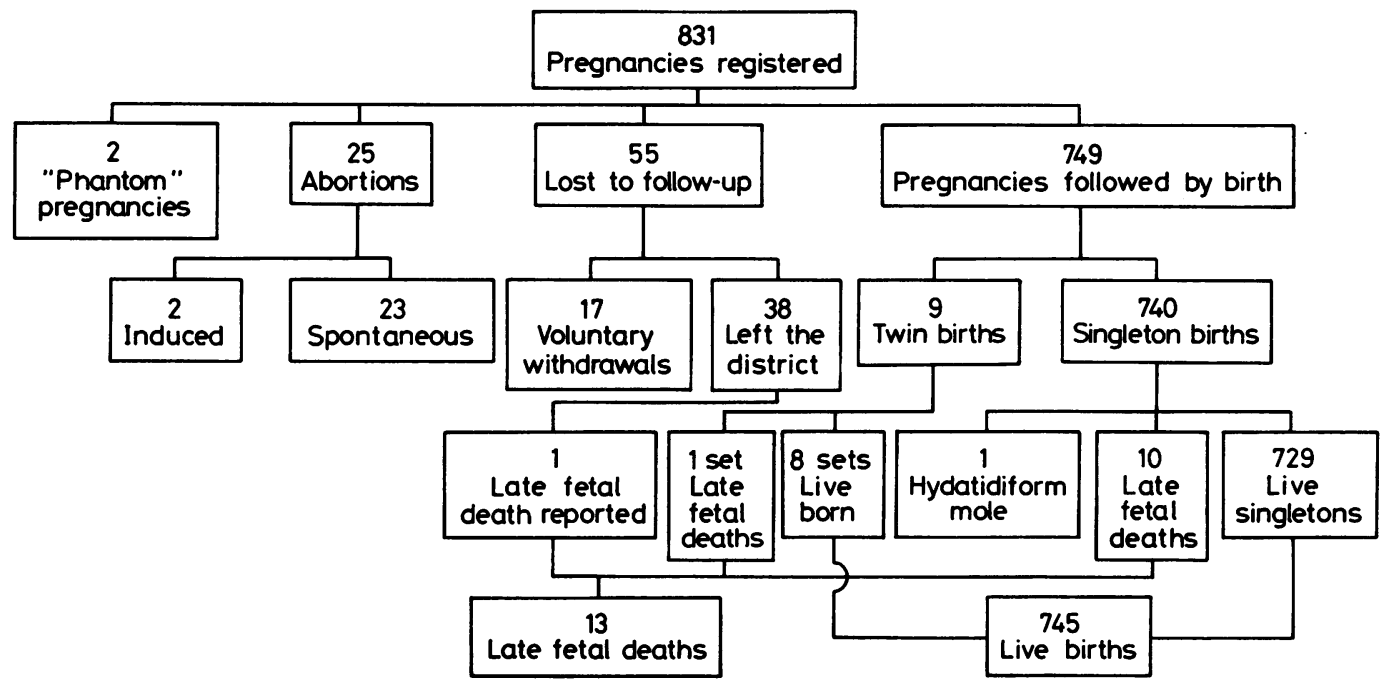

Diagrammatic representation of the outcome of pregnancy in the cohort of pregnant women originally enrolled for study.

BLOOD LEAD CONCENTRATIONS

The mean blood lead concentrations $(\mathrm{PbB})$ at all stages of gestation (with the exception of 21-29 weeks) were statistically significantly higher in the PP than in the NP women (table 2). As indicated by the magnitude of the standard errors, variation between individual women was not great. For example, at 14-20 weeks' gestation only nine women had levels greater than $20 \mu \mathrm{g} / \mathrm{dl}$ and none exceeded $32 \mu \mathrm{g} / \mathrm{dl}$. Since the mean values did not vary systematically with gestational stage, each woman's pre-delivery blood lead concentrations were combined to give an average value for use in some of the subsequent analyses.

\section{SPONTANEOUS ABORTION}

Of the 774 pregnancies followed to completion, 23 ended in spontaneous abortion before the 20 th week of gestation. Since only one of these occurred in the

Table 2 Mean venous blood lead concentrations by stage of pregnancy: Port Pirie versus Non-Port Pirie women (numbers of women in parentheses)

\begin{tabular}{llr}
\hline & \multicolumn{2}{l}{ Mean blood lead $(\mu g / d l) \pm$ standard error } \\
\cline { 2 - 3 } Pregnancy stage (weeks) & Port Pirie & Non-Port Pirie \\
\hline$<14$ & $10 \cdot 8 \pm 0 \cdot 24(248)$ & $7 \cdot 7 \pm 0 \cdot 61(9)$ \\
$14-20$ & $10 \cdot 6 \pm 0 \cdot 17(531)$ & $7 \cdot 6 \pm 0 \cdot 19(171)$ \\
$21-29$ & $11 \cdot 0 \pm 0 \cdot 53(67)$ & $10 \cdot 9 \pm 1 \cdot 60(8)$ \\
$30-36$ & $10 \cdot 7 \pm 0 \cdot 19(519)$ & $7 \cdot 6 \pm 0 \cdot 21(172)$ \\
Delivery & $11 \cdot 2 \pm 0 \cdot 21(512)$ & $7 \cdot 5 \pm 0 \cdot 25(150)$ \\
Umbilical cord & $10 \cdot 1 \pm 0 \cdot 19(500)$ & $6 \cdot 2 \pm 0 \cdot 22(172)$ \\
\hline
\end{tabular}

NP women, analysis of spontaneous abortion was confined to the pregnancies enrolled from within Port Pirie.

Maternal blood lead concentrations were available for 19 of the 22 abortions occurring in PP women The mean $\mathrm{PbB}$ of $11 \cdot 3 \pm 0 \cdot 81 \mu \mathrm{g} / \mathrm{dl}$ was not statistically significantly higher than the mean level of $10 \cdot 8 \pm 0 \cdot 15 \mu \mathrm{g} / \mathrm{dl}$ for all other PP pregnancies extending beyond 20 weeks' gestation.

In multivariable analysis, none of: woman's age, years lived in Port Pirie, marital status, country of birth, race, systolic or diastolic blood pressure, nor maternal $\mathrm{PbB}$ was associated with risk of spontaneous abortion.

PRE-TERM DELIVERY

There were 749 pregnancies followed beyond the 20th week of gestation for which there was a satisfactory recorded outcome. After excluding nine twin pregnancies, and 10 for which gestational age was not recorded, there were 730 pregnancies in which estimated gestational age was recorded by dates (ie, time since last menstrual period) and 673 in which a Dubowitz assessment of neonatal maturity was recorded.

With pre-term delivery defined as birth before the 37 th week of pregnancy (stillbirths included), the proportion of pre-term deliveries was higher in the PP pregnancies $(5.3 \%)$ than in the NP pregnancies $(2.9 \%)$ (table 3$)$. When defined by neonatal maturity the proportions were $4.3 \%$ and $1.9 \%$, respectively. These differences, based on small numbers, are not statistically significant. 
Table 3 Numbers and proportions of singleton pregnancies terminating in pre-term delivery, as defined by estimated gestational age (dates) and by neonatal maturity: Port Pirie versus Non-Port Pirie pregnancies (numbers of late fetal deaths in parentheses)

\begin{tabular}{|c|c|c|c|c|c|c|c|c|}
\hline \multirow{3}{*}{$\begin{array}{l}\text { Place of } \\
\text { residence }\end{array}$} & \multicolumn{4}{|c|}{$\begin{array}{l}\text { Gestational age* } \\
\text { (dates) }\end{array}$} & \multicolumn{4}{|c|}{$\begin{array}{l}\text { Neonatal maturity }{ }^{\dagger} \\
\text { (Dubowitz assessment) }\end{array}$} \\
\hline & \multicolumn{2}{|c|}{$<37 w k s$} & \multicolumn{2}{|c|}{$\geqslant 37 w k s$} & \multicolumn{2}{|c|}{$<37$ wks } & \multicolumn{2}{|c|}{$\geqslant 37 w k s$} \\
\hline & No. & $\%$ & No. & $\%$ & No. & $\%$ & No. & $\%$ \\
\hline Port Pirie & $30(7)$ & $5 \cdot 3$ & $527(2)$ & $94 \cdot 7$ & 22 & $4 \cdot 3$ & 494 & $97 \cdot 5$ \\
\hline Non-Port Pirie & $5(1)$ & $2 \cdot 9$ & $168(0)$ & $97 \cdot 1$ & 3 & 1.9 & 154 & $98 \cdot 0$ \\
\hline
\end{tabular}

*No value recorded for 11(1) deliveries (the late fetal death occurred in a PP mother).

+ No value recorded for 67 neonates.

Among PP women, maternal PbB at delivery was obtained for 23 of the 30 pre-term (by dates) births occurring and for 17 of 22 such births classified as pre-term delivery by neonatal assessment. The umbilical cord $\mathrm{PbB}$ concentrations were available for 17 of each of these two categories of pre-term delivery (table 4). For each of the four comparisons, the mean $\mathrm{PbB}$ was higher for the pre-term deliveries than for the other births.

In subsequent multivariable analysis carried out on all PP pregnancies, of the 10 non-lead variables initially considered, none was statistically significantly related to the risk of pre-term delivery. The net estimates of the relative risk of pre-term delivery (by dates) associated with categories of $\mathrm{PbB}$, maternal social status (derived from husband's occupation), and four other previously reported risk factors, as estimated by multiple logistic regression analysis, are shown in table 5 .

There is a dose-dependent association of the risk of pre-term delivery with maternal $\mathrm{PbB}$ at delivery (table 5). Compared with women with $\mathrm{PbB}$ of $8 \mu \mathrm{g} / \mathrm{dl}$ or less, women with $\mathrm{PbB}$ of $9-11$ or $12-14 \mu \mathrm{g} / \mathrm{dl}$ have $2 \cdot 1$ or 3.0 times the risk respectively, while the highest exposure group (with a mean of $17 \cdot 1 \mu \mathrm{g} / \mathrm{dl}$ ) have a $4 \cdot 4$-fold increase in risk of pre-term delivery.

Table 4 Comparison of mean blood lead levels $( \pm S E)$ in pre-term deliveries, and all other births, as measured in maternal blood at delivery and in umbilical cord blood: Port Pirie pregnancies (numbers of pregnancies in parentheses)

\begin{tabular}{|c|c|c|c|}
\hline \multirow[b]{2}{*}{$\begin{array}{l}\text { Method of } \\
\text { assessment }\end{array}$} & \multirow[b]{2}{*}{$\begin{array}{l}\text { Pregnancy } \\
\text { outcome }\end{array}$} & \multicolumn{2}{|c|}{ Mean blood lead concentration ( $\mu \mathrm{g} / \mathrm{dl}$ ) } \\
\hline & & $\begin{array}{l}\text { Maternal blood, } \\
\text { at delivery }\end{array}$ & $\begin{array}{l}\text { Umbilical } \\
\text { cord blood }\end{array}$ \\
\hline Gestational age (dates) & $\begin{array}{l}\text { Pre-term } \\
\text { Other }\end{array}$ & $\begin{array}{l}12 \cdot 5 \pm 1 \cdot 2 \quad(23) \\
11 \cdot 2 \pm 0 \cdot 2(482)\end{array}$ & $\begin{array}{l}12.7 \pm 1.6 \quad(17)^{*} \\
10.0 \pm 0.2(478)\end{array}$ \\
\hline Neonatal & $\begin{array}{l}\text { Pre-term } \\
\text { Other }\end{array}$ & $\begin{array}{l}13 \cdot 9 \pm 1 \cdot 3(17)^{*} \\
11 \cdot 3 \pm 0 \cdot 2(453)\end{array}$ & $\begin{array}{l}12 \cdot 2 \pm 1 \cdot 3 \\
10 \cdot 2 \pm 0 \cdot 2(449)\end{array}$ \\
\hline
\end{tabular}

"Statistically significantly different from the mean $\mathrm{PbB}$ for all other births, $\mathrm{p}<0.05$.
Table 5 Estimates of relative risk of pre-term delivery (by dates), from multiple logistic regression analysis of maternal blood lead concentration at delivery and other relevant maternal variables: all singleton Port Pirie pregnancies including late fetal deaths

\begin{tabular}{|c|c|c|c|}
\hline Variable & Categories & Relative risk & $\begin{array}{l}95 \% \text { confidence } \\
\text { interval }\end{array}$ \\
\hline Age & $\begin{aligned} \leqslant & 21 \\
& 22-29 \\
\geqslant & 30\end{aligned}$ & $\begin{array}{l}1 \\
0.7 \\
0.3\end{array}$ & $\begin{array}{ll}0 \cdot 2, & 2 \cdot 1 \\
0 \cdot 1, & 2 \cdot 0\end{array}$ \\
\hline Gravidity & $\begin{array}{r}0 \\
1 \\
>1\end{array}$ & $\begin{array}{l}1 \\
0.3 \\
0.6\end{array}$ & $\begin{array}{ll}0.1, & 1 \cdot 1 \\
0.2, & 1.9\end{array}$ \\
\hline Social status & $\begin{array}{l}\text { low } \\
\text { high }\end{array}$ & $\begin{array}{l}1 \\
0.4\end{array}$ & $0 \cdot 1,1 \cdot 0$ \\
\hline Occupation & $\begin{array}{l}\text { outside home } \\
\text { home duties }\end{array}$ & $\begin{array}{l}1 \\
1 \cdot 1\end{array}$ & $0 \cdot 4,2 \cdot 9$ \\
\hline Blood lead $(\mu \mathrm{g} / \mathrm{dl})$ & $\begin{array}{l}\leqslant 8 \\
>8, \leqslant 11 \\
>11, \leqslant 14 \\
>14\end{array}$ & $\begin{array}{l}1 \\
2 \cdot 1 \\
3 \cdot 0 \\
4 \cdot 4\end{array}$ & $\begin{array}{l}0 \cdot 6,7 \cdot 6 \\
0 \cdot 8,11 \cdot 3 \\
1 \cdot 2,16 \cdot 8\end{array}$ \\
\hline Smoking (cigs/day) & $\begin{array}{r}0 \\
\leqslant 10 \\
>10\end{array}$ & $\begin{array}{l}1 \\
0.5 \\
0.6\end{array}$ & $\begin{array}{l}0 \cdot 1,1.6 \\
0 \cdot 1,2.9\end{array}$ \\
\hline
\end{tabular}

If $\mathrm{PbB}$ is treated as a continuous variable in logistic regression analysis, there is a $1 \cdot 11$-fold increase in the risk of pre-term birth with each $1 \mu \mathrm{g} / \mathrm{dl}$ increase in $\mathrm{PbB}$. Thus a rise of $3 \mu \mathrm{g} / \mathrm{dl}$ in $\mathrm{PbB}$ (equivalent to the difference in mean PbB between PP and NP pregnancies) would increase the risk of pre-term delivery by a factor of $1 \cdot 11^{3}=1 \cdot 37$, ie, by $37 \%$.

Since late fetal death may itself cause pre-term delivery, analyses were repeated with late fetal deaths excluded. This exclusion markedly increased the strength of association of pre-term delivery with increasing blood lead concentration, with the point estimates of relative risk for the four $\mathrm{PbB}$ categories (table 5) becoming $1 \cdot 0,2 \cdot 7,6 \cdot 1$, and $8 \cdot 7$ respectively.

Further analyses examined how this gradient in risk of pre-term delivery varied for blood lead determinations made at other stages of pregnancy. The gradient was clearly weakest for the early blood sample (14-20 weeks), increasing markedly for the next sample ( $>20$ weeks), and marginally higher again at the time of delivery.

The $\mathrm{PbB}$-associated gradient in risk was similar for pre-term delivery as assessed by the Dubowitz procedure.

\section{LATE FETAL DEATH (LFD)}

Of 740 non-twin pregnancies followed satisfactorily beyond the 20th week of pregnancy, 11 terminated in late fetal death (stillbirth); 10 of these were in PP women.

The proportion of LFDs was higher in the PP pregnancies ( 17.5 per 1000 live births) than in the NP pregnancies ( 5.8 per 1000 live births). From data 
supplied by the Australian Bureau of Statistics (ABS) for the calendar period 1978-82, the equivalent figure for South Australia overall was 8.0 LFDs per 1000 live births. (Further, the official ABS figure for Port Pirie during 1978- 82 was $17 \cdot 1$, which approximates the figure of 17.5 within our study cohort.)

The maternal mid-pregnancy (14-20 week) mean $\mathrm{PbB}$ was $10 \cdot 3 \pm 0.8 \mu \mathrm{g} / \mathrm{dl}$ in the $10 \mathrm{PP}$ pregnancies ending in LFD, compared with $9 \cdot 9 \pm 0 \cdot 2 \mu \mathrm{g} / \mathrm{dl}$ in all other pregnancies. However, at delivery (mean gestational age 30.9 weeks) the mean maternal $\mathrm{PbB}$ was $7 \cdot 2 \pm 0.9$ as compared with $10 \cdot 4 \pm 0 \cdot 2$ for the live births; this difference is statistically significant $(\mathrm{p}<0.05)$.

\section{NEONATAL MORPHOLOGY}

Each neonate's weight, crown-heel length, and head circumference were measured. Part of the overall variation in these measurements is attributable to variables which were of secondary interest in this study. Therefore, in each of the multiple regression analyses investigating associations of blood lead with size and shape, apparent effects due to gender and gestational age at birth (linear and quadratic terms), mother's pre-pregnant Quetelet's Index (weight corrected for height), maternal height, smoking habits, and prior parity were all taken into account.

Since pre-term delivery is a determinant of neonatal size, and has been considered as a separate outcome (see above), multiple regression analyses of the predictors of size and shape were restricted to singletons with a gestational age of 37 weeks or more. Errors were assumed to be normally distributed; the linearity of plots of ordered residuals against the appropriate normal order statistic indicated that this assumption was reasonable.

\section{Birthweight}

Among the 721 pregnancies for which birthweight was recorded, after exclusion of twin pregnancies, the proportion resulting in low birthweight $(<2500 \mathrm{~g}$ at gestational age of 37 weeks or more) was higher in the PP pregnancies $(3.9 \%)$ than in the NP pregnancies $(1 \cdot 8 \%)$. After stratification by cigarette smoking habits, this difference persisted. The probability of low birthweight was approximately three times higher in smokers $(6.9 \%)$ than in non-smokers $(2 \cdot 0 \%)$.

Mean $\mathrm{PbB}$, in maternal blood at delivery and in cord blood, was consistently lower in low birthweight pregnancies than in other pregnancies. However, none of these differences was statistically significant (table 6).

In multiple regression analysis, wherein $21 \%$ of the variance in birthweight was explained in terms of the
Table 6 Mean maternal blood lead concentration $( \pm S E)$ in relation to birthweight $(<2500 \mathrm{~g} v>2500 \mathrm{~g})$ : Port Pirie and Non-Port Pirie pregnancies separately (numbers of pregnancies in parentheses)

\begin{tabular}{|c|c|c|c|c|}
\hline \multirow{3}{*}{$\begin{array}{l}\text { Place of } \\
\text { residence }\end{array}$} & \multicolumn{4}{|c|}{ Maternal blood lead concentration ( $\mu \mathrm{g} / \mathrm{dl}$ ) } \\
\hline & \multicolumn{2}{|l|}{ At delivery } & \multicolumn{2}{|c|}{ Umbilical cord } \\
\hline & $<2500 \mathrm{~g}$ & $\geqslant 2500 \mathrm{~g}$ & $<2500 \mathrm{~g}$ & $\geqslant 2500 \mathrm{~g}$ \\
\hline Port Pirie & $\begin{array}{l}10 \cdot 4 \pm 1 \cdot 1 \\
(17)\end{array}$ & $\begin{array}{l}11 \cdot 2 \pm 0 \cdot 21 \\
(464)\end{array}$ & $\begin{array}{l}9 \cdot 6 \pm 0 \cdot 90 \\
(18)\end{array}$ & $\begin{array}{l}10 \cdot 0 \pm 0 \cdot 20 \\
(459)\end{array}$ \\
\hline Non-Port Pirie & $\begin{array}{l}5 \cdot 5 \pm 0 \cdot 1 \\
(2)\end{array}$ & $\begin{array}{l}7 \cdot 6 \pm 0 \cdot 26 \\
(142)\end{array}$ & $\begin{array}{l}3.4 \pm 0.69 \\
\text { (2) }\end{array}$ & $\begin{array}{l}6 \cdot 2 \pm 0 \cdot 23 \\
(138)\end{array}$ \\
\hline Totals & $\begin{array}{l}9 \cdot 8 \pm 1 \cdot 1 \\
(19)\end{array}$ & $\begin{array}{l}10 \cdot 4 \pm 0 \cdot 19 \\
(606)\end{array}$ & $\begin{array}{l}9 \cdot 0 \pm 0 \cdot 91 \\
(20)\end{array}$ & $\begin{array}{l}9 \cdot 1 \pm 0 \cdot 17 \\
(612)\end{array}$ \\
\hline
\end{tabular}

variables of secondary interest (infant's sex, gestational age, maternal relative weight, cigarette smoking, prior parity), all variables except prior parity and maternal blood lead were statistically significantly associated with birthweight.

A total of 68 out of 714 infants $(9 \cdot 5 \%)$ were recorded as being "small for dates" (ie, weight is lesso than the tenth percentile for the appropriate gestational age). Multiple logistic regression analysis迹 revealed that the risk of such intrauterine growth retardation was unrelated to maternal $\mathrm{PbB}$.

\section{Crown-heel length}

In multiple regression analysis, nearly $12 \%$ of the total variation in neonatal crown-heel length was explicable in terms of the variables of secondary interest. Because there may well have been procedural differences in methods used by the various hospitals for determining length, analysis in relation to $\mathrm{PbB}$ was restricted to neonates born to $\mathrm{PP}$ women only. No association between blood lead and crown-heel length was detected.

\section{Head circumference}

Secondary variables accounted, in multiple regression analysis, for $15 \%$ of the total variation in head circumference. A statistically significant inverse relation of head circumference to maternal $\mathrm{PbB}$ $(-0.03 \mathrm{~cm}$ per $\mu \mathrm{g} \mathrm{Pb} / \mathrm{dl})$ was observed, but this may have been due to procedural differences between hospitals. The relation did not persist when analyses were restricted to neonates of PP women only.

PREMATURE RUPTURE OF MEMBRANES Of the 672 deliveries for which the time lapse between rupture of membranes and the onset of labour was recorded, $21(3 \cdot 1 \%)$ experienced premature rupture of membranes, defined as a delay of at least 24 hours. In neither the PP nor the NP pregnancies was there an obvious, or consistent, 
difference in the mean maternal $\mathrm{PbB}$ at delivery or in the mean umbilical cord $\mathrm{PbB}$ between those with and without premature rupture of membranes.

Multiple logistic regression analysis yielded a statistically significant association of premature rupture of membranes with the mother's educational status, while smoking, alcohol intake, and $\mathrm{PbB}$ were not related to premature rupture of membranes.

Completeness of placental membranes was recorded at delivery. For the 15 deliveries with incomplete membranes, the mean maternal $\mathrm{PbB}$ at delivery was $13.4 \mu \mathrm{g} / \mathrm{dl}$ compared with $10.7 \mu \mathrm{g} / \mathrm{dl}$ in all other pregnancies.

\section{CONGENITAL ANOMALIES}

A total of 40 infants $(5.4 \%)$ were classified (at birth) as having congenital anomalies. Only one had multiple anomalies, and 29 were classified as minor. After controlling for the putative risk factors of maternal age, gravidity, social status, smoking and alcohol usage, no association with blood lead level at 14-20 weeks or later was apparent.

\section{DIFFICULTIES IN CONCEIVING}

Concern over the time taken to become pregnant was reported by 105 study subjects. In logistic regression analysis, after a strong association of this self-perceived difficulty with increasing age had been taken into account, there was no association with $\mathrm{PbB}$ in the first blood sample taken in the subsequent pregnancy.

\section{Discussion}

Epidemiological and animal experimental research has shown pregnancy outcome to be influenced by many environmental, behavioural, and biomedical factors. Recent prospective studies have demonstrated how environmental chemicals, ${ }^{10}$ maternal smoking and drinking, ${ }^{11}$ and maternal nutritional status ${ }^{12}$ influence the risk of various adverse outcomes of pregnancy. There is also substantial evidence of deleterious effects of lead, and other heavy metals, upon pregnancy outcome. ${ }^{13-15}$ In epidemiological studies, therefore, there are methodological difficulties in apportioning the "effects" on pregnancy outcome between environmental lead exposure and the many other coexistent risk factors.

A second limitation of this present study is that there was relatively little variation in inter-individual blood lead concentrations among the women resident in Port Pirie. Further, the mean absolute concentrations were not high, being in the range $11-12 \mu \mathrm{g} / \mathrm{dl}$ in PP women and 8-9 $\mu \mathrm{g} / \mathrm{dl}$ in the NP women. The levels in the PP women are similar to those reported for adult women in urban settings in a number of other surveys. ${ }^{16}$ These mean $\mathrm{PbB}$ values differ markedly from those subsequently observed in this study's cohort of children. Average values of approximately $25-30 \mu \mathrm{g} / \mathrm{dl}$ were observed at both 15 months and 24 months of age in the $40 \%$ of children living nearest to the lead smelter and its fallout zone, while the remaining PP children had mean $\mathrm{PbB}$ levels of approximately $20 \mu \mathrm{g} / \mathrm{dl}$ (unpublished data).

Animal experimental research indicates that lead can adversely affect reproduction via a variety of biological mechanisms: pre-gestational effects (gametotoxicity and mutagenesis) upon either parent; effects upon gestation (including implantation, placental integrity; hormonal phenomena and parturition); effects upon the fetus (teratogenesis and fetal development); and neonatal effects (survival, maternal nurturing, and the effects of lead exposure via lactation). ${ }^{13}$ However, few of these effects are demonstrable in experimental animal models at levels of lead uptake considered equivalent to those in environmentally exposed human populations.

Placental transfer of lead to the human fetus appears to begin around the 12 th to the 14 th week of gestation $^{17}$ (which indicates that the fetus may be exposed to elevated lead levels while the major period of neurogenesis is in progress). ${ }^{18}$ Thus, with the exception of spontaneous abortion occurring before this stage of gestation, the various adverse outcomes of pregnancy examined in this study could all reflect, to some extent, a direct influence of lead on either the placental interstitial tissue or the fetal tissues.

The lack of any clear positive association of spontaneous abortion with maternal $\mathrm{PbB}$ within this study population suggests that small, non-occupational increases in lead exposure are insufficient to disrupt the early stages of pregnancy. Human lead exposure at higher levels than in this study population is a well-documented cause of spontaneous abortion, rates being consistently elevated 5- to 10-fold in occupationally exposed women from earlier decades. ${ }^{1}$

Similarly, there are early reports of an increased risk of pre-term delivery associated with lead exposure ${ }^{1}$ and a more recent report from Missouri, -USA. ${ }^{2}$ The latter study also showed a fourfold increase in both maternal and fetal blood lead levels in the pre-term deliveries compared with those delivered normally. In our study, a lesser, but statistically significant, increasing gradient in the risk of pre-term delivery in association with increasing maternal blood lead was observed, after controlling for the effects of other covariates. 
Early reports of pregnant women occupationally exposed to lead often included evidence of an increased proportion of LFDs. ${ }^{1}$ Likewise, animal experimental data show an increased perinatal mortality following maternal lead exposure. ${ }^{15}$ In two studies of lead concentrations in, respectively, brain and rib samples, LFD babies had substantially higher levels than did other babies dying of assorted (mostly accidental) causes. $^{1920}$ In this study, however, although the subset of PP women within this cohort had a higher proportion of LFDs than did the NP women, LFD was negatively associated with individual maternal $\mathrm{PbB}$.

Measures of birthweight (including IUGR) and neonatal morphology were not related to maternal $\mathrm{PbB}$. Few data pertaining to these outcomes have been previously reported. An experimental study in rats has shown reductions in litter size, birthweight, and neonatal survival with increased maternal antenatal lead exposure. ${ }^{21}$

In contrast to the Missouri study, ${ }^{2}$ premature rupture of membranes was quite unrelated to maternal $\mathrm{PbB}$ (or to umbilical cord $\mathrm{PbB}$ ). The placentas from this study have been stored for biochemical measurement, and the relation of placental tissue lead concentration to premature rupture of membranes will be examined.

Placental lead will also be examined in relation to the other pregnancy outcomes reported in this paper. There is evidence that, for genetic or other reasons, there is variation between individuals in the avidity with which the fetus and/or the placenta take up elements and substances from the maternal blood. ${ }^{12}$ Thus, certain pregnancy outcomes may be more closely related to concentrations of lead in the placenta than in the maternal blood.

In summary, the data from this cohort study indicate, firstly, that within a residential environment known (from other survey data) to cause substantial elevations of blood lead concentration in children aged 1-5 years, there is only a small to moderate increase in $\mathrm{PbB}$ within adult women, and, secondly, that with the exception of pre-term delivery this modestly elevated $\mathrm{PbB}$ is not associated with perceptible increases in the risk of any of the adverse outcomes of pregnancy considered here.

We acknowledge the excellent cooperation of families in Port Pirie and surrounding towns who were involved in this study, their doctors, and the staff of local hospitals. The study benefited greatly from the skilled participation of Barbara Hobson, $\mathrm{RN}$, who served as nurse coordinator for the first three years, assisted by Mary-Anne Lange, RN, and Bronwen Morgan, RN. We also thank members of the Adelaide Children's Hospital Chemical Pathology Department (Ms B King, Mr R Oldfield, and Dr A Pollard) who undertook the lead assays, staff of the CSIRO Division of Human Nutrition who assisted with data analysis (Ms M Padhye, Ms J Rogers, Ms J Syrette), and Mr C Greeneklee, Manager of the Commonwealth Health Department Laboratory in Port Pirie. The study was partially supported by a grant from the National Health and Medical Research Council.

Requests for reprints to: Dr AJ McMichael, Division of Human Nutrition, Commonwealth Scientific and Industrial Research Organization (Australia), Kintore Avenue, Adelaide, South Australia, 5000.

\section{References}

${ }^{1}$ Rom WN. Effects of lead on the female and reproduction: a review. Mt Sinai J Med 1976; 43: 544-52.

${ }^{2}$ Fahim MS, Fahim Z, Hall OG. Effects of subtoxic lead levels on pregnant women in the State of Missouri. Res Commun Chem Pathol Pharmacol 1976; 13: 309-15. D)

${ }^{3}$ Vistica DT, Ahrens FA, Ellison WR. The effects of lead $\frac{\text { D }}{\supset}$ upon collagen synthesis and proline hyroxylation in the Swiss mouse 3 T6 fibroblast. Arch Biochem Biophys 1977; 177: 15-23.

${ }^{4}$ White JM, Selh HS. Lead and the red cell. Br J Haematol 1975; 30: 133-8.

${ }^{5}$ Angell NF, Lavery JP. The relationship of blood lead levels to obstetric outcome. Am J Obstet Gynecol 1982; 142: $40-6$.

${ }^{6}$ Needleman HL, Rabinowitz M, Leviton A, Linn S, Schoenbaum $S$. The relationship between prenatal exposure to lead and congenital anomalies. $J A M A$ 1984; 251: 2956-9.

${ }^{7}$ Australian Standard Project No. CH/006-0030. Method for the determination of lead in whole blood (Electrothermal Atomization Atomic Absorption spectrophotometric method), (1984) (in press).

${ }^{8}$ Dubowitz LMS, Dubowitz V, Goldberg BA. Clinical assessment of gestational age in the newborn infant. $J$ Pediatrics 1970; 77: 1-10.

${ }^{9}$ Thomson AM, Billewicz WZ, Hytten FE. The assessment of fetal growth.J Obstet Gynaec (Brit Comm) 1968; 75: 903-16.

${ }^{10}$ Gibson GT, Colley DP, Baghurst PA. Maternal exposure to environmental chemicals and the aetiology of teratogenesis. Aust NZ J Obstet Gynaec 1983; 23: $170-4$.

${ }^{11}$ Gibson GT, Baghurst PA, Colley DP. Maternal alcohol, tobacco and cannabis consumption and the outcome of pregnancy. Aust NZ J Obstet Gynaec 1983; 22: 15-9.

${ }^{12}$ McMichael AJ, Dreosti IE, Gibson GT, Hartshorne JM, Buckley RA, Colley DP. A follow-up study of serial maternal zinc levels and pregnancy outcome. Early Human Development 1982; 7: 59-62.

${ }^{13}$ Silbergeld EK. Effects of lead on reproduction: Review of experimental studies. In: Rutter $\mathbf{M}$, Russell Jones R, eds. Lead versus health. London: John Wiley and Sons, 1983; 217-27.

${ }^{14}$ Wynn M, Wynn A. Lead and human reproduction. London: CLEAR, 1982. 
${ }^{15}$ Nogaki $\mathrm{K}$. On action of lead on body of lead refinery workers: particularly on conception, pregnancy, and parturition in case of females, and on vitality of their newborn. Excerpta Med 1958; 4: 2176.

${ }^{16}$ Duggan MJ. Lead in dust as a source of children's body lead. In: Rutter M, Russell Jones $\mathrm{R}$, eds. Lead versus health. London: John Wiley and Sons, 1983; 115-39.

${ }^{17}$ Barltop D. Transfer of lead to the human fetus. In: Barltop D, Barland WL, eds. Mineral metabolism in pediatrics. Philadelphia: Davis, 1969; 135-51.
${ }^{18}$ Dobbin J, Sands J. Quantitative growth and development of human brain. Arch Dis Child 1973; 48: 757-67.

${ }^{19}$ Schroeder HA, Tipton IH. The human body burden of lead. Arch Environ Health 1968; 17: 965.

${ }^{20}$ Bryce-Smith D, Deshpande RR, Hughes J, Waldson HA. Lead and cadmium levels in stillbirths. Lancet 1977; i: 1159.

${ }^{21}$ Stowe HD, Goyer RA. The reproductive ability and progeny of $F_{1}$ lead-toxic rats. Fertil Steril 1971; 22: 755-60. 